\title{
Aproximar el sector salud a la vida cotidiana de las personas
}

\section{Gladys Vergara-Palacios ${ }^{1}$}

\author{
${ }^{1}$ Universidad Católica Sedes Sapientiae. \\ Facultad de Ciencias de la Salud. \\ Licenciada en Enfermería.
}

Recibido: 08-08-2017 Aprobado: 31-08-2017

Citar como: Vergara G.

Aproximar el sector salud a la vida cotidiana de las personas. CASUS. 2017;2(2):80-81.
El sistema de salud en el Perú corresponde a un sistema mixto pues los bienes proceden tanto del sector público como del privado. Las fuentes de financiamiento emanan del recaudo fiscal (Sub sector público), las cotizaciones (Seguridad social) y los seguros privados. Si bien se viene afianzando el proceso del aseguramiento universal este aún no es total para toda la población peruana. Entre sus debilidades principales se encuentran la superposición de redes, ausencias de complementariedad de servicios y continuidad de cuidado, e imposibilidad de atención integral (1).

Dando complejidad a lo anterior se encuentran los riesgos para la salud que están ampliamente distribuidos en la población. Sin embargo, los individuos difieren en cuanto a la magnitud del riesgo que corren, más que en si están expuestos al riesgo o no. En consecuencia, la categorización binaria en «expuesto» y «no expuesto» no consigue reflejar la importancia de las relaciones continuas entre factores de riesgo y enfermedad (2).

En este contexto difícil la prevención de la enfermedad emana desde los servicios de salud y está dirigida a la modificación de las conductas de riesgo. En este sentido la salud familiar es un tema prioritario de toda acción de prevención. Debido a que se encuentra en un nivel de exposición permanente se debe incidir en acciones para disminuirlo. Entre ellas se mencionan la concientización, valoración y el aprendizaje sobre el manejo del riesgo $(1,2)$.

Muchas estrategias de reducción de riesgos comprenden un componente de cambio conductual (2). Incluso soluciones de tipo técnico como el abastecimiento de agua potable por tuberías no se traducirán en mejoras sanitarias a menos que la población esté dispuesta a utilizar las nuevas fuentes. Los sociólogos sostienen que todo cambio de comportamiento requiere la comprensión previa del problema. La manera de traducir esa comprensión en un comportamiento saludable depende de las preferencias o características del individuo. Entre ellas su mayor o menor aversión a los riesgos para la salud y el valor asignado a una posible pérdida de la misma frente a otras opciones vitales como son la riqueza o un estilo de vida $(1,2)$. 


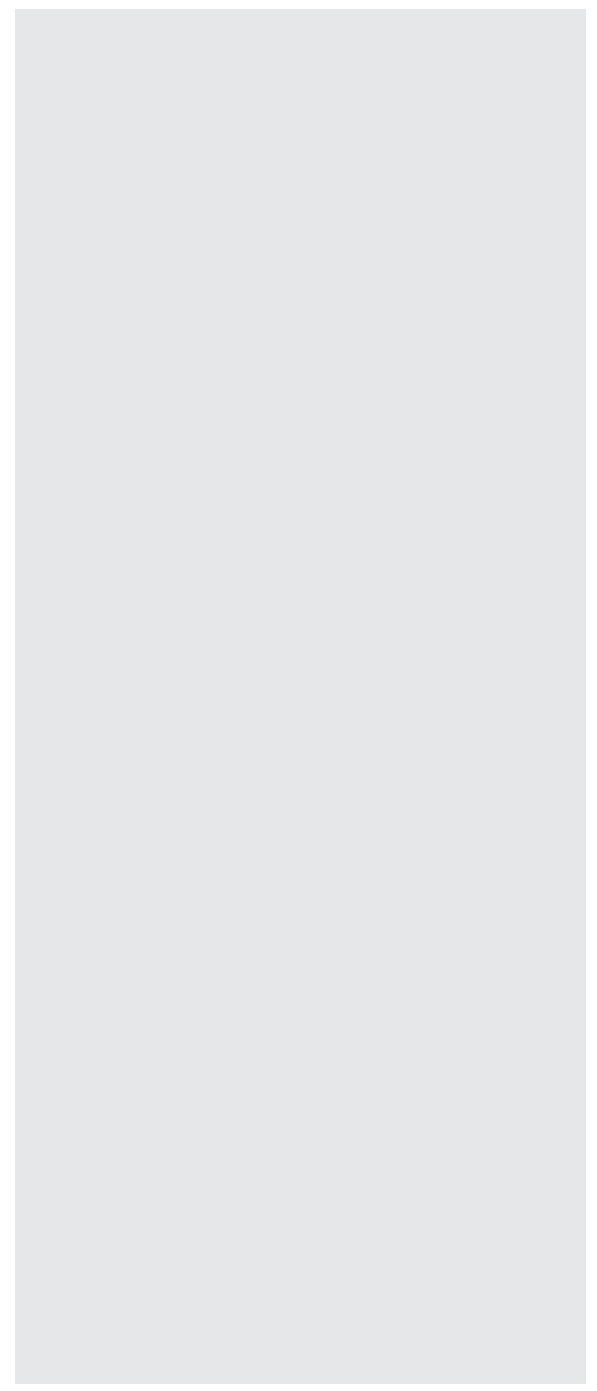

Un punto débil en este fenómeno es la orientación de las políticas sanitarias del sistema de salud hacia la asistencia médica reparativa, primando un enfoque eminentemente biomédico. Por ello, una parte importante de la labor científica y la mayoría de los recursos sanitarios se dirigen hacia el tratamiento de las enfermedades. O sea, predomina el principio de la "asistencia a persona en peligro" (3). No se ha entendido completamente que el concepto de salud sobrepasa la noción de ausencia de enfermedad y debe ser considerada como un proceso social-político indisoluble de los otros procesos sociales, económicos, políticos, culturales y familiares que se producen en una sociedad.

A pesar de los adelantos en el diagnóstico y tratamiento de las enfermedades son las acciones de prevención las más activas para conseguir una vida sana y digna. En la prestación de los servicios de salud del primer nivel de atención las acciones dirigidas a la prevención (donde también están incluidas las de promoción de la salud) deben ocupar un lugar preponderante. Estas acciones permiten incrementar los niveles de salud de la población evitando que esta se enferme. En comparación a los altos costos que genera la atención de la salud recuperativa, la prevención, sin embargo, se realiza a un costo menor (4).

Lo que se requiere ahora es una acción concertada y darle la prioridad a la Atención Primaria de Salud. La realidad peruana cuenta solo con un primer nivel de atención y con programas verticales de pobre calidad. La reducción de riesgos y la promoción de una vida sana tendrán en todo el Perú amplios y duraderos efectos sociales, que no se limitarán a la mera prevención de muertes y discapacidades. Por lo tanto, promover el fortalecimiento de la atención integral de salud basada en la persona, la familia y la comunidad representa una gran prioridad. O sea, es necesario aproximar el sector salud a la vida cotidiana de las personas, superando las barreras de acceso a los servicios hoy reconocidos.

\section{REFERENCIAS BIBLIOGRÁFICAS}

1. Consejo Nacional de Salud. Lineamientos y medidas de reforma del sector salud. Lima: Ministerio de Salud;2013.

2. Jáuregui C, Suárez P. Promoción de la salud y prevención de la enfermedad. 1a ed. Colombia: Panamericana;1997.
3. Tejada D. ¿Qué sucedió con la salud para todos? Veinticinco años después de Alma-Ata. Rev Perspectivas de Salud. 2003;8(2):3-7.
4. Villar M. Factores determinantes de la salud: Importancia de la prevención. Acta Médica Peruana. 2011;28(4):237-241. 